\title{
Embryonic stem cell production through therapeutic cloning has fewer ethical problems than stem cell harvest from surplus IVF embryos
}

\section{J-E S Hansen}

$\ldots \ldots \ldots \ldots \ldots \ldots$
Correspondence to:
Dr J-E S Hansen, Centre for
Rare Diseases and
Disabilities, Bredgade 25,
1260 Copenhagen K,
Denmark; jesh@dadlnet.dk
Revised version received
28 August 2001
Accepted for publication
28 August 2001

J Med Ethics 2002;28:86-88

Restrictions on research on therapeutic cloning are questionable as they inhibit the development of a technique which holds promise for succesful application of pluripotent stem cells in clinical treatment of severe diseases. It is argued in this article that the ethical concerns are less problematic using therapeutic cloning compared with using fertilised eggs as the source for stem cells. The moral status of an enucleated egg cell transplanted with a somatic cell nucleus is found to be more clearly not equivalent to that of a human being. Based on ethical considerations alone, research into therapeutic cloning should be encouraged in order to develop therapeutic applications of stem cells.
$\mathrm{P}$ roduction of embryonic stem cells from unfertilised egg cells transplanted with a nucleus from, for example, a patient cell, ("therapeutic cloning") may result in immunologically compatible replacement tissues in severe degenerative or inherited diseases such as Huntington's chorea, Parkinson's disease, multiple sclerosis or cystic fibrosis. ${ }^{1-3}$ At present research and development involving human embryonic stem cells is restricted in many countries, and in some only the use of embryonic stem cells derived from the blastocyst stage (day six) of fertilised eggs that are in surplus from fertility treatment is recommended. ${ }^{4-6}$ Specifically, the Council of Europe has prohibited the creation of human embryos for research purposes. As stem cell based treatment may be beneficial to patients suffering from severe disease and as therapeutic cloning may offer a way to generate clinically superior stem cells, the present resistance to allowing this technique to be developed through research may seem unethical at first glance. The resistance, however, is a result of two overriding concerns.

First, the harvesting of stem cells includes the destruction of the pre-embryo at the blastocyst stage, and if the pre-embryo at this stage is recognised as a human being with an inalienable right to life this would prohibit stem cell harvest whether the blastocyst were a result of therapeutic cloning or came from a surplus fertilised egg.

Second, the technique of therapeutic cloning is the same technique as that used in the initial stage of reproductive cloning, where an enucleated egg cell is transplanted with a somatic cell nucleus and implanted in a susceptible uterus in order to produce an infant. Development of therapeutic cloning may therefore be feared to pave the way ("slippery slope") for an otherwise unacceptable use, and this risk may be considered sufficiently great to prohibit therapeutic cloning despite the potential benefits to patients.

\section{DIFFERENCES IN NATURE}

Would a human being resulting from reproductive cloning be a normal human with full human rights? Judging from animal experiments where it has been possible to bring progeny to full term birth after initial transfer of a somatic cell nucleus to an enucleated egg cell it is difficult to foresee that such a being would be anything other than fully human. Experience with reproductive cloning of animals shows that there is a significant risk that a cloned human being would have a shortened life span and/or that it would have various inborn disabilities or malfunctions. ${ }^{78}$ At present, this known risk would make human reproductive cloning unethical. But like other human beings born with chromosomal abnormalities or genetic disorders there will probably be no doubt that a cloned human is a full human being in every important respect. If that is the case one is naturally confronted with the question whether an enucleated human egg transplanted with a somatic cell nucleus-a "transnuclear egg cell" - is any different from a fertilised egg which would normally be the start of the process leading to a human being. And if there are no significant differences then it would follow that an egg cell with a nuclear transplant is a human being to the same extent that a fertilised egg is—or is not—a human being. I suggest, however, that the biological differences might be morally significant.

The genetic complement of the fertilised egg is a unique result of a fusion of a sperm cell and an egg cell, and this may naturally evolve into an embryo, a fetus, and eventually an infant. This is not the case with an enucleated egg cell that has been transplanted with the nuclear material from a somatic cell. Neither is the genetic content unique, for it is identical with the nuclear donor; nor is it occurring naturally, with a natural potential of evolvement into an embryo. It is entirely artificial and leads its life in the laboratory unless somebody chooses to implant it into a susceptible female uterus before it can develop to the blastocyst stage, when stem cell harvest is possible.

Among the arguments put forward for considering a fertilised egg to be a human being one key argument is that the genome is unique from fertilisation onwards and that the development of a unique individual is a consequence of the workings of this unique genome. It is argued (for example in Donum Vitae) that the individual person is determined by the unique genome, and from the time this genome arises, one should consider the person to be present.'

The genome in question is the nuclear genome, for the mitochondrial DNA of the egg cell cytoplasm is not unique to a particular fertilised egg since it is inherited without the recombination at fertilisation between the maternal and paternal nuclear DNA. Indeed, apart from random mutations 
occuring rather infrequently, the mitochondrial DNA is identical through the maternal bloodline over generations. Therefore, the uniqueness of every human person cannot in any case be based on mitochondrial DNA, and the fact that in a transnuclear egg cell the nuclear genome is combined with a non-natural mitochondrial genome has no bearing on the genetic uniqueness which it is suggested is the basis for human uniqueness. To use an analogy one might say that the heart (= mitochondrial DNA) in a heart transplant patient has no relevance for the identity of the patient even though the combination is "unique" in this particular patient.

Apart from the reductionism implied, in my opinion the entire argument of deriving human uniqueness from genetic uniqueness is flawed since identical twins have identical genomes but are evidently separate individuals. However, if emphasis is none the less placed on the uniqueness of the new genetic complement (the nuclear genome) of a fertilised egg the differences between a fertilised egg and a transnuclear egg cell would be significant and the transnuclear egg cell could not be considered a human being even if a naturally fertilised egg cell were to be so considered. The genome of the transnuclear egg cell already exists in the cells of the donor of the nucleus. So either one must give up the notion that human individuality is related to genetic uniqueness or accept that a transnuclear egg cell is not a human individual.

It has been argued that all existing humans have started as a fertilised egg and as this is perceived to be the common root of all human beings a special moral significance must be warranted. ${ }^{6}$ The fertilised egg has been the natural beginning of every human being regardless of whether this has come about through sexual intercourse, artificial insemination, or in vitro fertilisation. It is therefore argued that the purpose, embedded in nature itself, of a fertilised human egg is to develop into a human being.

While the concept of natural purpose may be dubiousconsider for instance that the great majority of naturally fertilised eggs perish before term-the purpose of a transnuclear egg cell is clearly not defined by nature..$^{10}$ Therefore, if emphasis is placed on the natural purpose of a fertilised egg to evolve into an embryo and eventually a human being, the transnuclear egg cell would fall outside the category of human beings as there are no natural occurrences whereby a transnuclear egg cell develops into a fetus. As with all other artifacts, its purpose is properly defined through human design.

It may therefore be questionable whether the biological in vitro entity resulting from therapeutic cloning should be considered a human embryo or pre-embryo at all. Rather it seems to be a modified egg cell that might be turned into an embryo through further artificial procedures.

\section{POTENTIALITY}

It could be argued that the potential of an in vitro blastocyst to develop into a fetus after a series of contingent procedures, including successful implantation, confers a special moral status whether the blastocyst is a result of in vitro fertilisation or a result of nuclear transfer from a somatic cell to an unfertilised, enucleated egg cell. The "potentiality" argument has been used to argue in favour of the full human moral status of the fertilised egg from fertilisation onwards: what might naturally (that is, without further external intervention) become a human being should be considered a human being already.

In the strict sense "potential" means that an entity can perform or be something that it at present doesn't or isn't. This requires first, identity (that is, that it remains what it is in some key aspect) and second that the potential is inherent (that is, that it doesn't require something essential from outside). In the case of the in vitro blastocyst having potential for personhood neither of these two conditions are met. Evidently the blastocyst cannot be a newborn child, it may become one, and while this process could happen "in the ordinary course of events", it might also result in two or more children (twinning) or it might not happen at all, whether through natural malfunction or through a decision not to implant the fertilised or transnuclear egg. From this it may be seen that neither is identity necessarily preserved nor is the process independent of external conditions and contingent decisions by other actors. Although the in vitro blastocyst may form an essential basis for the subsequent emergence of a person it isn't one in itself, and human moral status cannot be inferred from a potential which it doesn't inherently have in the first place.

Nevertheless, on the basis of the essential role the fertilised egg or blastocyst has in the formation of the biological matrix from which a person could emerge one might decide to confer some special respect or moral status on it or even respect it as if it were a human person. Whether such a social construct is well founded falls outside the scope of this paper, but it has been discussed elsewhere. ${ }^{11}$

\section{CHANGING STATUS}

As with any other cell of the human body, the unfertilised egg cell is a physical component of a human being. Isolated in culture, in the laboratory, as human cells are in thousands of laboratories, such cells are biological matter without any reasonable claim to special rights or status by themselves, even though they are indeed human and alive, just as are blood cells donated for transfusion or organs donated for transplantation. If experiments are made with such cell cultures this does not change the moral status of the cells. Chemical components may be injected, DNA transferred and life extinguished without such cells changing moral status. If the nucleus is removed and another put in, and the transnuclear cell grown for a few days while dividing and forming a culture as all cells will do in the proper artificial circumstances, would this make a human being appear when the cell in question was an egg cell rather than, say, a muscle cell? Clearly not. The knowledge that if further potential procedures were in fact undertaken, namely transfer into a prepared female uterus at a specific time, this might subsequently result in a pregnancy and eventually the birth of a "cloned" human being, cannot change the status of the transnuclear egg cell from a cell in culture to a human being in unusual circumstances. This would run contrary to all cause-effect relations both temporally and logically.

\section{APPEARANCE OF HUMAN MORAL STATUS}

So, it would seem that an egg cell in moral respects is just like any other cell, and that it doesn't change moral status after it has been enucleated and subsequently transplanted with a nucleus from a somatic cell. After implantation in a uterus, however, and at least after nine months of cell divisions and further development, an unquestionably human being may evolve. If one considers personhood to be something inherent rather than a social construct, then there must necessarily be a time when the human personhood appears. For the transnuclear egg cell the earliest time could possibly, though not necessarily, begin after the last contingent, artificial intervention would have been necessary - that is, when the transnuclear egg cell was implanted in a susceptible female uterus.

Implantation is, at the present technological stage, an absolute requirement, and it must take place in a very brief window of time (in the first two to four days of development). If the transnuclear egg cell is not implanted, further development in vitro allows formation of the blastocyst, from which stem cells may be harvested, but embryonic and fetal development does not take place. So, in the series of decisions and manipulations in vitro which a transnuclear egg used to establish a pregnancy would have been the object of before it passes beyond the direct voluntary control of the technician 
(and others), implantation is the last, contingent artificial intervention. If it is decided to implant the transnuclear egg at the right time, it will begin embryonic development; if it is decided not to implant, the transnuclear egg will form an in vitro culture from which stem cells can be harvested, and these stem cells may possibly be kept alive for many years in embryonic stem cell banks without any reason to suggest that cells or tissues derived therefrom should begin to develop personhood and human moral status.

Recognising that an implanted transnuclear egg changes status and develops human personhood at some time within the nine months of pregnancy, implantation represents the earliest possible timepoint when this may begin to happen. One might also say the same for an in vitro fertilised egg, but as the previous sections have shown, the case for the transnuclear egg cell not being endowed with personhood or human moral status is even stronger than for the fertilised egg, and consequently the necessity of a change in status is that much clearer.

If as a result of some future technical development blastocysts could be maintained in culture and fetal development sustained, a human being would eventually emerge. The time at which this emergence might be possible depends on the criteria used for personhood. Twinning may occur spontaneously until formation of the primitive streak after 14 days of pre-embryonic development and until that time individuality is not a property of the pre-embryo. As individuality is a sine qua non for personhood it seems safe to consider 14 days of normal embryonic development to be the minimum requirement before a human being can emerge. Other criteria might place the earliest timepoint at a later stage, for example 28 days, when the neural tube closes and the development of the central nervous system necessary for rationality begins. Or, with Aristotle and St Thomas Aquinas, one might consider 40-90 days of development to be necessary to allow a human soul to be present; or, as the Roman Catholic Church taught for centuries, one might require body-form and movement to be present before full human status was recognised..$^{12}$ In the context of stem cell harvest from the inner cell mass of the blastocyst at day six, which is about the time when an IUD ("coil") blocks implantation in women using this device to avoid pregnancy, none of these considerations of the earliest possible time for emergence of a human being support the blastocyst as a person.

\section{THE SLIPPERY SLOPE}

Having considered the possible moral status of the transnuclear egg cell resulting from therapeutic cloning and having found that stem cell production including destruction of the blastocyst does not violate the fundamental human right to life, it may still be warranted to prohibit this technique as it may be percieved to pave the way for reproductive cloning. There is no inherent necessity, however, why this should be so. Refinement of the technique of therapeutic cloning to produce stem cells does not automatically result in reproductive cloning. It requires a separate decision to implant the transnuclear egg cell before it reaches the blastocyst stage where stem cell harvest is possible. Indirectly, the technical expertise learned from therapeutic cloning could be seen as instrumental in reproductive cloning, as could other kinds of technical expertise involving, for example, cell culture or hormonal regulation.
If therapeutic cloning is recognised as of potential benefit to patients, where no other curative remedies exist, it seems ethically questionable to block development of this technology based on a hypothetical misuse of that technology. Generalising such a position to other areas of medicine one would quickly end in absurdity. It would clearly be unethical to abstain from treating a heart patient with digitalis based on the fear that somebody else might use digitalis as a deadly poison. If reproductive cloning should not be allowed to happen, then that is what should be prohibited. Specifically this would require prohibition of implantation in a female uterus of a transnuclear egg cell.

\section{CONCLUSION}

Six days after in vitro fertilisation or nuclear transplantation the blastocyst forms a ball of cells. From this biological matter in vitro, pluripotent stem cells or other biological products of value for the treatment of medical illnesses may be derived without compromising the fundamental human right to life, even though such a procedure entails the destruction of the blastocyst and thus the irreversible elimination of the possibility for fetal development after implantation into a uterus. Production of embryonic stem cells from transnuclear unfertilised egg cells seems to entail even fewer ethical problems than harvest of stem cells from fertilised eggs in surplus from fertility treatment. And that, combined with the considerable therapeutic potential offered by the production of immunologically compatible-and perhaps even genetically modified-tissue from such transnuclear stem cells, should make somatic nuclear transfer into unfertilised egg cells a preferred technique that warrants encouraging incentives and focused research effort, rather than legal restrictions.

\section{REFERENCES}

1 Liu S, Qu Y, Stewart TJ, et al. Embryonic stem cells differentiate into oligodendrocytes and myelinate in culture and after spinal cord transplantation. Proceedings of the National Academy of Science USA 2000;97:6126-31.

2 Schuldiner M, Yanuka O, Itskovitz-Eldor J, et al. Effects of eight growth factors on the differentiation of cells derived from human embryonic stem cells. Proceedings of the National Academy of Science USA 2000;97:11307-12

3 Munsie MJ, Michalska AE, O'Brien CM, et al. Isolation of pluripotent embryonic stem cells from reprogrammed adult mouse somatic cell nuclei. Current Biology 2000;10:989-92.

4 Lenoir N. Europe confronts the embryonic stem cell research challenge. Science 2000;287: 1425-7

5 Nuffield Council on Bioethics. Stem cell therapy: the ethical issues. London: Nuffield Council on Bioethics, 2000.

6 Det Etiske Råd. Kloning. Copenhagen: The Danish Council of Ethics, 2001.

7 Hill JR, Roussel AJ, Cibelli JB, et al. Clinical and pathologic features of cloned transgenic calves and fetuses (13 case studies). Theriogenology $1999 \cdot 51: 1451-65$

8 Smith LC, Bordignon V, Babkine M, et al. Benefits and problems with cloning animals. Canadian Veterinary Journal 2000;41:919-24.

9 Congregation for the Doctine of the Faith. Instruction on respect for human life in its origin and on the dignity of procreation (Donum vitae). Acta Apostolica Sedis 1988;80:65-105.

10 Hertig AT. The overall problem in man. In: Benirschke K, ed. Comparative aspects of reproductive failure. New York:Springer Verlag 1967:1 1-41.

11 Watt H. Potential and the early human. Journal of Medical Ethics 1996:22:222-6.

12 Donceel JF. Immediate animation and delayed hominization. Theological Studies 1970;31:76-105. 